\title{
Pain in hospitalized children: A prospective cross- sectional survey of pain prevalence, intensity, assessment and management in a Canadian pediatric teaching hospital
}

\author{
Elsa M Taylor MBChB FANZCA ${ }^{1}$, Kristina Boyer RN MSc${ }^{2}$, Fiona A Campbell BSc MD FRCA ${ }^{3}$
}

EM Taylor, K Boyer, FA Campbell. Pain in hospitalized children: A prospective cross-sectional survey of pain prevalence, intensity, assessment and management in a Canadian pediatric teaching hospital. Pain Res Manage 2008;13(1):25-32.

BACKGROUND: Pain is under-recognised and undertreated. Although standards now exist for pain management, it is not known if this has improved care of hospitalized children.

OBJECTIVES: To benchmark pain prevalence, pain intensity, pain assessment documentation and pharmacological treatment of pain. The aim was to highlight areas of good practice, identify areas for improvement and inform development of hospital standards, education, future audits and the research agenda.

METHODS: The present prospective cross-sectional survey of all medical and surgical inpatient units took place on a single day at the Hospital for Sick Children (Toronto, Ontario), a Canadian tertiary and quaternary pediatric hospital. A structured, verbally administered questionnaire was used to obtain information on patient demographics, pain before admission, pain intensity during admission and pain treatment. Charts were reviewed to establish frequency of documented pain assessment, the pain assessment tool used and analgesics given. Subgroup analysis was included for age, sex, visible minority or fluency in English, medical versus surgical services and acute pain service input.

RESULTS AND CONCLUSIONS: Two hundred forty-one (83\%) of the 290 inpatients or their carergivers were interviewed. It was found that $27 \%$ of patients usually had pain before admission, and $77 \%$ experienced pain during admission. Of these, $23 \%$ had moderate or severe pain at interview and $64 \%$ had moderate or severe pain sometime in the previous $24 \mathrm{~h}$. Analgesics were largely intermittent and single-agent, although $90 \%$ of patients found these helpful. Fifty-eight per cent of those with pain received analgesics in the preceding $24 \mathrm{~h}$ but only $25 \%$ received regular analgesia. Only $27 \%$ of children had any pain score documented in the preceding $24 \mathrm{~h}$. It was concluded that pain was infrequently assessed, yet occurred commonly across all age groups and services and was often moderate or severe. Although effective, analgesic therapy was largely single-agent and intermittent. Widespread dissemination of results to all professional groups has resulted in the development of a continuous quality assurance program for pain at the Hospital for Sick Children. A re-audit is planned to evaluate changes resulting from the new comprehensive pain strategies.

Key Words: Inpatient pain; Pain assessment; Pain intensity; Pain management; Pain prevalence; Pediatric pain

\author{
La douleur chez les enfants hospitalisés : enquête \\ prospective, transversale, sur la prévalence, \\ l'intensité, l'évaluation et la prise en charge de la \\ douleur dans un hôpital d'enseignement pédiatrique \\ au Canada
}

CONTEXTE : La douleur n'est pas reconnue assez souvent et elle n'est pas traitée suffisamment. Bien qu'il existe maintenant des normes relatives à la prise en charge de la douleur, on ne sait pas si celles-ci ont permis d'améliorer les soins aux enfants hospitalisés.

BUTS : L'enquête avait pour but d'établir des points de référence en ce qui concerne la prévalence, l'intensité, l'évaluation de la douleur et la documentation afférente ainsi que le traitement médicamenteux. Elle visait également à mettre en évidence les zones de pratiques exemplaires, à cerner les zones susceptibles d'amélioration et à contribuer, par son apport, à l'élaboration de normes hospitalières, à la formation, aux vérifications futures et au programme de recherche. MÉTHODE : L'enquête prospective, transversale a été menée au cours d'une seule journée dans tous les services internes de médecine et de chirurgie de l'Hospital for Sick Children, à Toronto, hôpital pédiatrique de soins tertiaires et quaternaires. Nous avons recueilli les renseignements sur les données démographiques des malades, la douleur avant l'hospitalisation, l'intensité de la douleur pendant le séjour à l'hôpital et le traitement de la douleur à partir d'un questionnaire oral, structuré. Nous avons également passé en revue les dossiers pour relever la fréquence de l'évaluation documentée de la douleur, les outils d'évaluation utilisés et les analgésiques administrés. Il y a eu analyse de sous-groupes selon l'âge, le sexe, les minorités visibles, la fluidité verbale en anglais, les services de médecine ou de chirurgie et la participation du service de traitement de la douleur aiguë.

RÉSULTATS ET CONCLUSIONS : Nous avons interrogé 241 (83\%) enfants hospitalisés sur 290 ou leurs fournisseurs de soins. Résultats : $27 \%$ des enfants avaient généralement de la douleur avant l'hospitalisation et $77 \%$ ont éprouvé de la douleur pendant le séjour à l'hôpital. Parmi eux, 23 \% ressentaient une douleur modérée ou intense au moment de l'entretien et $64 \%$ avaient connu des périodes de douleur modérée ou intense au cours des $24 \mathrm{~h}$ précédant l'entretien. La plupart du temps, les analgésiques étaient administrés en monothérapie, de manière intermittente, mais $90 \%$ des patients les trouvaient tout de même utiles. Cinquante-huit pour cent des enfants qui éprouvaient de la douleur avaient reçu des analgésiques au cours des 24 h précédentes, mais $25 \%$ seulement en recevaient régulièrement. Il y a eu une évaluation documentée de la douleur au cours des $24 \mathrm{~h}$ précédentes chez $27 \%$ seulement des enfants. Nous sommes arrivés à la conclusion que la douleur était évaluée peu fréquemment, bien que la pratique fût courante dans tous les groupes d'âge et dans tous les services, et que celle-ci était souvent modérée ou intense. L'analgésie, malgré tout efficace, consistait le plus souvent en l'administration intermittente d'un seul médicament. Une large diffusion des résultats à tous les groupes de professionnels a donné lieu à lélaboration d'un programme continu d'assurance de la qualité à l'Hospital for Sick Children. Une autre vérification est prévue afin d'évaluer les changements résultant de la mise en œuvre de nouvelles stratégies globales de prise en charge de la douleur.

${ }^{1}$ Department of Anaesthesia, Starship Children's Hospital, Auckland, New Zealand; '2Canuck Place Children's Hospice, Vancouver, British Columbia; ${ }^{3}$ Department of Anesthesia, Hospital for Sick Children, Toronto, Ontario

Correspondence: Dr Fiona A Campbell, Department of Anesthesia, Hospital for Sick Children, 555 University Avenue, Toronto, Ontario M5G

1X8. Telephone 416-813-7451, fax 416-813-7543, e-mail fiona.campbell@sickkids.ca 
$\mathrm{O}_{\mathrm{P}}^{\mathrm{n}}$ October 11, 2004, during the Global Day Against Pain, the World Health Organization (WHO), the International Association for the Study of Pain and the European Federation of the International Association for the Study of Pain Chapters issued a joint declaration supporting that "the relief of pain should be a human right". In addition to the obvious humane reasons for assessing and treating pain, there is evidence that untreated pain can have adverse physiological effects (1). While substantial evidence now exists regarding methods of effective pain assessment and management, it is not clear how well this knowledge is translated into clinical practice. For decades, many have reported that pain in hospitalized adults is both common and under-treated (2-4). Evidence from the few available publications suggests that this is also the case in hospitalized children (4-7). Inadequate pain relief in hospitalized patients led the Joint Commission on Accreditation of Healthcare Organizations in the United States to introduce standards in 2001 demanding pain assessment and management (8). Many national organizations, including the American Pain Society and local hospitals (including our own [the Hospital for Sick Children, Toronto, Ontario]) have endorsed this standard. Additionally, pain assessment is now a standard for Canadian Council on Health Services Accreditation, providing further impetus to ensure appropriate practice.

The Hospital for Sick Children is a 300 bed tertiary and quaternary pediatric hospital. Like many North American academic pediatric hospitals, it has a well-resourced, physicianled, advanced practice nurse-run acute pain service (APS), although only $5 \%$ of inpatients will access this service during their hospital stay. Therefore, the majority of pain management is instigated and managed by the patient's primary medical/surgical and nursing teams. In 2003, a Picker Patient Satisfaction survey of discharged patients from this hospital suggested that inpatients were receiving suboptimal pain management, reflecting what has also been shown in the few available studies done at other centres (4-7,9). A clinical audit was planned at the request of the Hospital Executive to further explore whether the retrospective patient satisfaction results held true. Because much of the existing published data are now over 10 years old, it was believed that an audit would contribute to more current findings on the state of pain assessment and management in hospitalized children (4-6,9). Although there are limitations to generalizability inherent in a single-centre study, the Hospital for Sick Children is likely representative of many pediatric tertiary care centres in its staffing mix, teaching and research responsibilities, and in the nature of diagnoses and conditions seen.

The purpose of the present prospective cross-sectional survey was to benchmark pain prevalence, pain intensity, pain assessment documentation and pharmacological treatment of pain in all medical and surgical inpatients, including those in critical care areas, on a typical day. The aim was to highlight areas of good practice, identify areas that need improvement and inform the development of hospital standards, education, future audits and the research agenda. The standards used for this audit were the well-accepted and nationally recognized targets for pain practices, namely, the Joint Commission on Accreditation of Healthcare Organizations/Canadian Council on Health Services Accreditation standard that pain should be assessed and documented regularly, and the WHO's standard that multimodal analgesics should be received regularly for the treatment of pain (10).

\section{METHODS \\ Setting, patients and procedures}

The present prospective cross-sectional study was approved by the local Research Ethics Board of the Hospital for Sick Children. Support was also obtained from the Child Health Services directors of the inpatient units. The goal was to survey all medical and surgical inpatients or caregivers on a single day, including those on the neonatal and critical care units, those with cognitive impairment and those where language was a barrier. Interpreters were organized if required. This was believed to be important, because there is evidence from the United States that non-English speaking adults may receive substandard pain management $(7,11)$. Children who had been transferred from one unit to another after the census were excluded because the data would not clearly reflect performance from either unit.

A single block of time on a weekday was chosen to provide a snapshot of pain experience, because it was most likely to represent a typical day in the Hospital for Sick Children. A single day was chosen to reduce the chance of advanced knowledge of an audit, which might increase vigilance to pain practices, thus potentially biasing the results. The patient population was identified from the 08:00 census on the day of the audit. The survey was undertaken in June 2004 by three pairs of researchers, each comprised of an anesthesiologist and a nurse. The survey consisted of a focused chart review and administration of a structured audit questionnaire. All researchers received training in the data collection methods. In particular, prompts or explanations of questions for the interview portion were standardized to limit inter-interviewer variability and bias. The interviewers were randomly allocated to different units within the hospital. The interviewer approached each eligible patient and/or caregiver. Before administering the questionnaire, verbal consent was obtained using a standardized consent script. The key points made to the interviewee were that the interviewer was not part of their direct patient care; the objective of the study was to improve pain management of all patients; no identifying data were being recorded although the health record would be reviewed; participation was voluntary and that it was not necessary to answer all of the questions; and finally refusal to take part would not interfere with patient care in any way. Patients were interviewed whenever possible. It was the interviewer's assessment of the child's developmental capacity to understand the questions and provide information on their pain and treatment that determined whether caregivers, usually parents, answered as proxy. This assessment was based on the child's age, diagnosis (eg, developmental delay) and current clinical status (eg, sedated, intubated). If required, clarification of a child's capacity to understand was obtained from parents and/or treating clinicians. When a parent answered the verbally administered questionnaire as proxy, the pain assessment was still obtained from the child if possible, and it was the child's assessment of pain that was used in the analysis of results. If the child or caregiver was absent on the initial visit, subsequent visits were attempted. If the child or caregiver was absent for three visits, they were not included. Children having offsite procedures were approached for participation once they returned to their unit. 
TABLE 1

The age ranges of the patients

\begin{tabular}{lc}
\hline Age, years & $\mathbf{n}$ \\
\hline$<1$ & 102 \\
1 to $<3$ & 33 \\
3 to $<5$ & 19 \\
5 to $<7$ & 18 \\
7 to $<10$ & 35 \\
10 to $<13$ & 31 \\
$\geq 13$ & 52 \\
\hline
\end{tabular}

\section{Measures}

Demographics: Demographic variables included age, sex, presence of a language barrier, or whether the patient was from a visible minority. Whether patients 'usually' had pain before admission as per patient or parent report, and whether they had seen the APS during admission was also recorded.

Pain prevalence and intensity: Patients were asked whether they had experienced any pain during their admission to hospital. If patients had no pain during their admission the interview was stopped. If patients had any pain during admission they were asked to rate both their pain intensity at interview and their worst pain intensity during the previous $24 \mathrm{~h}$ using a validated, simple four-point pain rating scale (none, small amount/little, medium amount/moderate, a lot/severe) (12). For clinical care a variety of validated, developmentally appropriate and standardized pain tools are used; for the purposes of the present audit a simple method was wanted to capture pain intensity in a wide range of ages. To facilitate completing the audit efficiently, a method that did not require much patient or family teaching, or numeric literacy was desirable. Furthermore, while scales such as the visual analogue scale or numeric rating scale are useful for monitoring the progress of a single patient, it has been suggested that a simple pain word rating scale has advantages in interindividual assessment (3).

Analgesia: Patients who had any pain during admission were asked whether they thought they had received any pain medicine. The type of analgesia given and the frequency of administration were obtained from the computerized patient health record. The use of conventional analgesics including acetaminophen, nonsteroidal anti-inflammatory drugs (NSAIDs), weak (ie, codeine) or strong (ie, morphine, fentanyl, hydromorphone) opioids and the use of epidural or regional analgesia were recorded, as well as whether they were given regularly or intermittently. The pain management index (PMI) as suggested by Strohbuecker et al (13) was calculated. The PMI was originally designed to assess the adequacy of pain treatment in adult cancer patients, and has since been used in other pain prevalence studies (13-20). The PMI is calculated by subtracting pain scores from analgesic scores. The pain scores are no pain $=0$, mild pain $=1$, moderate pain $=2$ and severe pain $=3$. The analgesic scores are according to the WHO ladder: no analgesic $=0$, WHOI (nonopioid analgesia) $=1$, WHOII $($ weak opioid $)=2$, WHOIII (strong opioid) $=3$. The PMI ranges from -3 to 3 ; negative scores indicate under-treatment. Positive scores do not necessarily represent over-treatment; a patient's pain score may be low because of appropriate analgesia provided by a strong opioid, thereby resulting in a positive PMI.

Pain assessment: The nursing flow-sheet has dedicated space for documentation of pain assessment scores and also contains

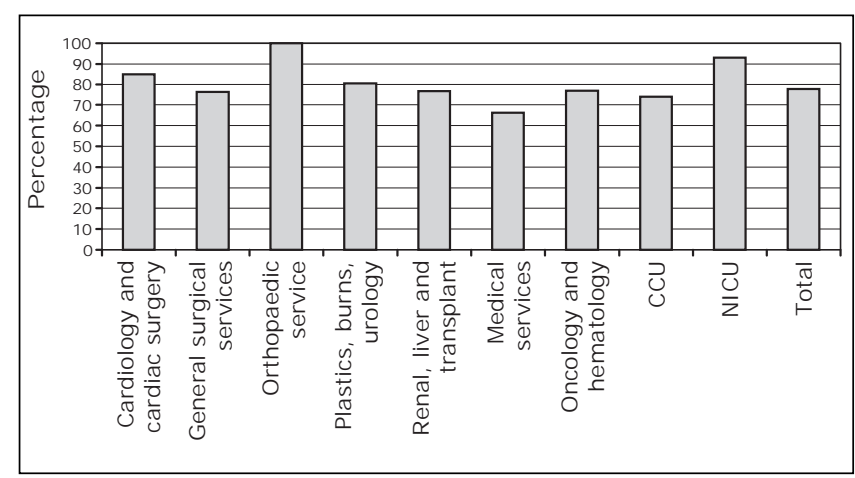

Figure 1) Prevalence of pain during admission by service. CCU Critical care unit; NICU Neonatal intensive care unit

information on the appropriate pain assessment tools recommended for use at the Hospital for Sick Children. The frequency of pain assessment documentation and the pain assessment tool used (if documented) were recorded. This information was sought for all patients, including those who said that they had no pain during their admission.

Confidential comments: At the end of the interview, the patient or caregiver was given an opportunity to provide comments to the interviewer regarding anything to do with pain management. A stamped addressed envelope was also provided should they wish to make confidential comments later.

\section{Analysis}

Statistical analysis was performed using the Excel 2004 Statistical package (Microsoft, USA). Descriptive statistics including CIs around prevalence data were used. Inferential nonparametric tests were utilized to test relationships among data and to generate hypotheses. Unless otherwise stated the $\chi^{2}$ test was used. The statistical test used and the $\mathrm{P}$ value are stated. $\mathrm{P}<0.05$ was considered to be significant.

\section{Demographics}

\section{RESULTS}

Of the 290 medical and surgical inpatients, 241 (83\%) were interviewed. Of the 49 patients not interviewed, one declined participation, and the other 48 were unavailable for interview. The reasons for not being available included: in the operating room $(n=5)$, discharged from hospital $(n=24)$, not available despite three visits $(n=6)$, patient transferred to another unit $(n=6)$, no interpreter available $(n=4)$, and child dying or just died $(n=3)$. There were equal numbers of boys and girls. The mean and median ages were 5.9 years and 4.2 years, respectively. Further information on the age distribution can be found in Table 1 . The principal interviewee was the child in $27.4 \%$ of interviews, the parents in $58 \%$ (when possible the current pain assessment was still obtained from the child) and the child's primary nurse in $4.6 \%$ (predominantly for neonatal intensive care unit patients when parents were unavailable). The principal interviewee was not recorded on $10 \%$ of the interview sheets.

\section{Pain}

Of the 241 inpatients interviewed, $77 \%$ (95\% CI $72 \%$ to $82 \%$ ) had some pain during admission. Pain occurred across all services and all groups of patients (Figure 1). Of those who experienced pain during admission, $23 \%$ had moderate or severe pain 


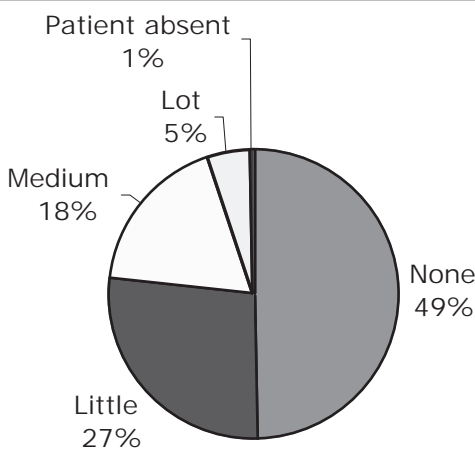

Figure 2) Pain intensity at interview among inpatients reporting any pain during admission

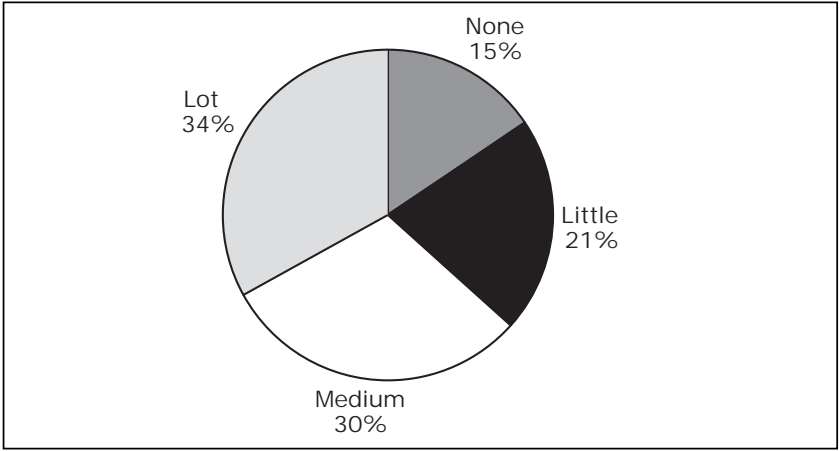

Figure 3) Worst pain intensity during the previous $24 \mathrm{~h}$ among inpatients reporting any pain during admission

TABLE 2

Further clinical detail on those patients having severe pain at the time of interview

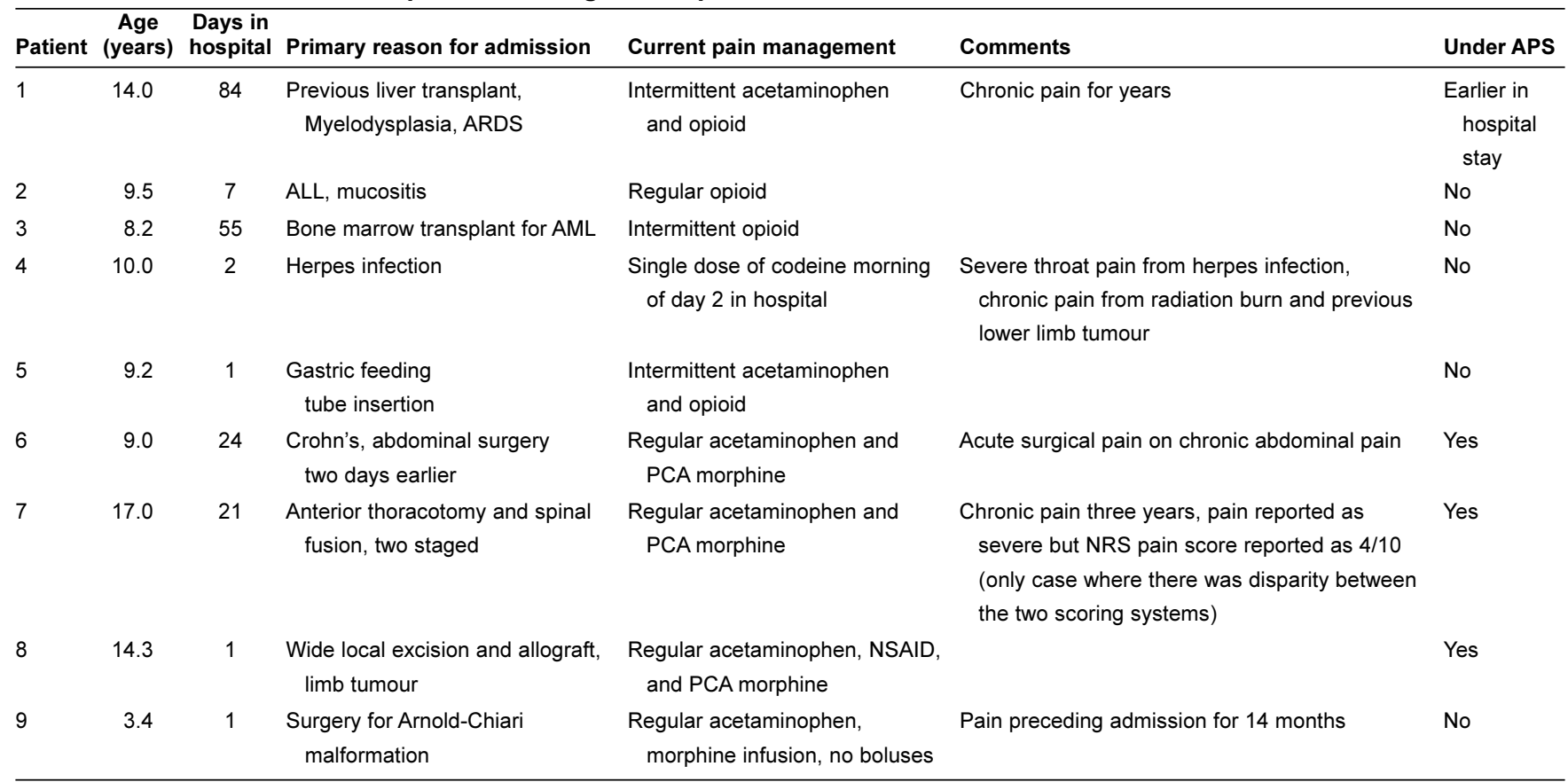

ALL Acute lymphocytic leukemia; AML Acute myeloid leukemia; APS Acute pain service; ARDS Acute respiratory distress syndrome; NRS Numeric rating scale; NSAID Nonsteroidal anti-inflammatory drug; PCA Patient-controlled analgesia

at interview (Figure 2) and 64\% had had moderate or severe pain at some time in the previous $24 \mathrm{~h}$ (Figure 3 ). Further clinical information is provided in Table 2 regarding those patients who had severe pain at the time of interview. Forty-nine per cent of patients were pain free at the time of interview and $15 \%$ had been pain free in the preceding $24 \mathrm{~h}$ (Figures 2 and 3 ).

Sixty-five patients (27\%) reported that they 'usually' had pain before admission. On further clarification, it was found that nine of these patients had pain that was short-term and clearly had not been present for more than three months, so these were excluded from this subgroup analysis. While time did not allow a full assessment, $22.8 \%$ (95\% CI $17.7 \%$ to $28.7 \%)$ of patients had pain that was potentially chronic. Significantly more $\left(\chi^{2}, \mathrm{P}<0.01\right)$ patients on the solid organ transplant, liver/renal and two hematalogy/oncology units 'usually' had pain ( $52 \%, 45 \%$ and $52 \%$, respectively).
Analgesia

When the patients who had experienced pain during admission were questioned, $44 \%$ thought that they had received no pain medicine in the preceding $24 \mathrm{~h}$. This was validated by the chart audit where it was confirmed that in the preceding $24 \mathrm{~h}$, $42 \%$ of the children who had experienced pain during admission had received no analgesia, 33\% had received it intermittently and only 25\% had received regular analgesia (Figure 4). While children with moderate or severe pain either at interview or in the preceding $24 \mathrm{~h}$ were more likely to receive analgesics $\left(\chi^{2}, \mathrm{P}<0.01\right.$ at interview, $\mathrm{P}<0.01$ for preceding $\left.24 \mathrm{~h}\right)$, only $30 \%$ received them regularly. When any analgesia was given, $90 \%$ (95\% CI $85 \%$ to $95 \%$ ) of patients found it helpful (Figure 5).

To assess the appropriateness of pain treatment, the PMI was calculated for all children who reported pain in the previous $24 \mathrm{~h}$. Of these, $47.3 \%$ had a PMI less than zero (ie, undertreated 


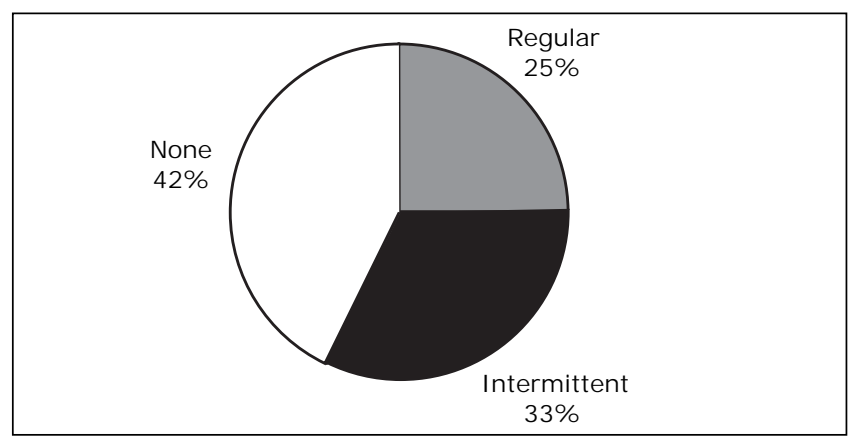

Figure 4) Frequency of analgesia administration among inpatients with pain

pain), 33.3\% had a PMI of zero and $19.4 \%$ had a PMI greater than zero. A PMI of zero or greater suggests that the analgesic given was appropriate; therefore, $52.7 \%$ of the present cohort received an appropriate type of analgesic for their pain intensity, although not necessarily at the needed frequency or dosage. This was the same whether the worst pain reported in the last $24 \mathrm{~h}$ was mild, moderate or severe $\left(\chi^{2}, \mathrm{P}=0.8\right)$. When patients whose worst pain was severe during the last $24 \mathrm{~h}$ were analyzed separately, $41 \%$ had received an opioid.

\section{Pain assessment}

Two hundred twelve questionnaires recorded reviewing patient charts to search for a documented pain assessment in the preceding $24 \mathrm{~h}$. Figure 6 shows the frequency of pain assessment documentation on these 212 charts. Eighteen per cent of children had three or more pain scores documented in the preceding $24 \mathrm{~h}$ and a further $9 \%$ had scores documented less frequently. Seventy-three per cent had no pain score documented during the preceding $24 \mathrm{~h}$.

\section{Subgroup analysis}

Sex: There was no sex difference in the frequency of pain assessment documentation $\left(\chi^{2}, \mathrm{P}=0.84\right)$, the presence of usual pain $\left(\chi^{2}, \mathrm{P}=0.17\right)$, having pain during admission $\left(\chi^{2}, \mathrm{P}=0.55\right)$ or the intensity of pain reported $\left(\chi^{2}, \mathrm{P}=0.94\right)$. There was also no difference in the analgesia received $\left(\chi^{2}, \mathrm{P}=0.90\right)$.

Visible minorities and patients with a language barrier: Information on whether a patient belonged to a visible minority or spoke English as a second language was available for 209 interviewed patients. Of the patients for whom this information was recorded, $42.1 \%$ belonged to a visible minority or spoke English as a second language. In this subgroup, there were no differences in the likelihood of usually having pain, having pain during admission $\left(\chi^{2}, \mathrm{P}=0.12\right)$, pain intensity, pain assessment, pain medication $\left(\chi^{2}, \mathrm{P}=0.2\right)$ or the likelihood of a referral to the APS $\left(\chi^{2}, \mathrm{P}=0.33\right)$.

Patients seen by the APS: Patients who were being seen or had been seen by the APS were more likely to have pain assessments documented (ANOVA, $\mathrm{P}<0.01$ ) and more likely to be receiving regular analgesia $\left(\chi^{2}, \mathrm{P}<0.01\right)$. They were more likely to report moderate and severe pain in the past $24 \mathrm{~h}$ and at the time of interview $\left(\chi^{2}\right.$, at interview $\mathrm{P}<0.01$, last $\left.24 \mathrm{~h} \mathrm{P}<0.05\right)$. Comparison of medical, surgical and intensive care units: Surgical units had fewer patients who 'usually' (patient determined) had pain before hospital admission. Hematology and oncology units had significantly more patients who 'usually' had pain $(\mathrm{P}<0.01)$. Patients on surgical units were more likely

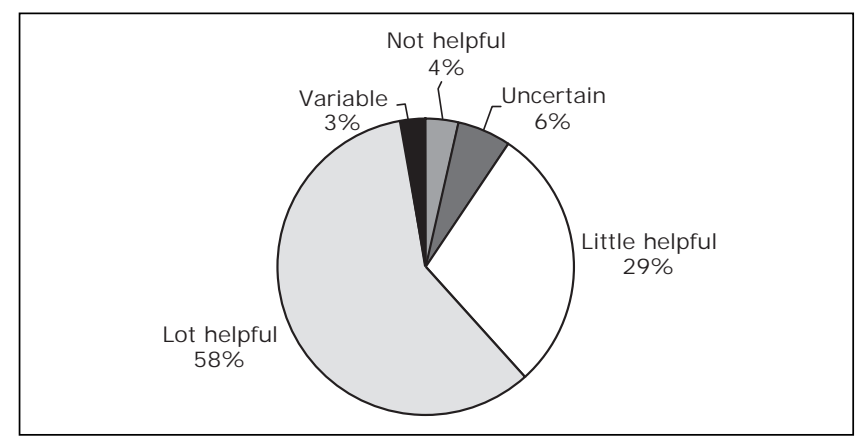

Figure 5) Helpfulness of analgesia reported by patients

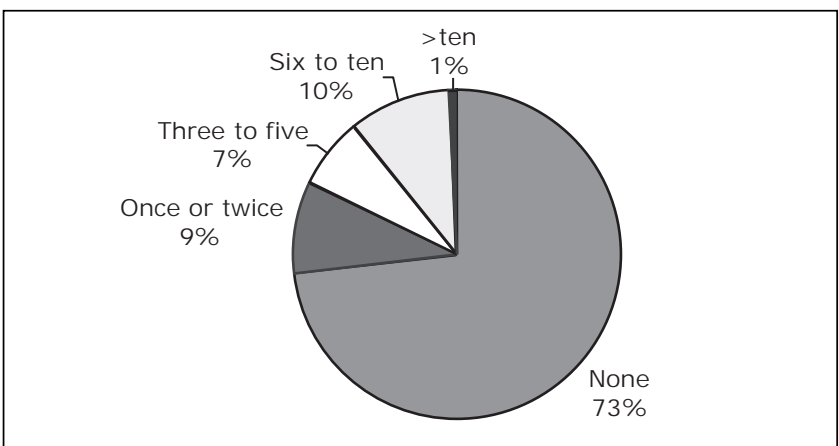

Figure 6) Frequency of pain assessment documentation on the 212 charts reviewed

to have higher pain scores in the preceding $24 \mathrm{~h}(\mathrm{P}<0.05)$ and more likely to receive analgesia $(\mathrm{P}<0.01)$. There were fewer patients on surgical units (31\% compared with $39 \%$ of those in intensive care and $58 \%$ of those on medical units) who had negative PMI scores (negative scores represent under-treatment of pain) $(\mathrm{P}<0.01)$.

Procedural pain: Although specific information on procedural pain was not sought, 25 patients commented that their pain was intermittent and related to procedures. However, their worst pain intensity in the preceding $24 \mathrm{~h}$ and their pain assessment was no different than the total group. They were less likely to have received analgesia $(\mathrm{P}<0.05)$.

\section{DISCUSSION}

Our results demonstrate that, even in a well-resourced tertiary referral pediatric centre, pain is common, under-recognised and undertreated. This occurred across all services incorporating a broad range of both medical and surgical conditions. However, when even simple analgesia was received, it was effective for most patients.

\section{Pain}

It is perhaps not surprising that $77 \%$ of children have some pain during admission to hospital, but it was disappointing that so many had moderate or severe pain in the previous $24 \mathrm{~h}$ $(64 \%)$ and even at the time of interview (23\%). Assuming that the day of the audit was fairly representative, one could extrapolate that nearly one-half of our inpatients may be experiencing moderate or severe pain on any given day. This is in keeping with previous publications $(4,9)$. Can this high level of pain intensity be explained by proxy pain assessments? It was difficult with our patient population and study design to avoid proxy assessment. Fifty per cent of our study population 
were younger than four years of age and we wanted to complete this 'snapshot' audit in a single day. We interviewed patients whenever possible and tried to get the pain assessment from the child even when parents answered the majority of the questionnaire. However, when the child was preverbal or cognitively impaired, we had a proxy pain assessment by a parent and occasionally by a nurse. We did not document whether the assessment was by patient or proxy. However, in a similar survey, children's self-reported pain intensity scores were highly correlated with parent ratings (21). There is also evidence, however, that both parent and nurse proxy assessments tend to underestimate pain $(22,23)$; thus, we may have underestimated pain within our institution.

It would have been useful to ask explicitly about procedural pain, because it may account for some of the moderate to severe pain intensity scores. However, 25 patients spontaneously commented that their pain was largely intermittent and related to procedures and when this subgroup was analyzed, the pain intensity scores for the last $24 \mathrm{~h}$ were not different from the larger group. This group was less likely to have received analgesics on the unit, although it is possible that they received offsite analgesia or sedation. Even if procedural pain had accounted for some of the moderate to severe pain, we have therapeutic modalities such as topical or systemic analgesia that should be employed to attenuate this pain.

Pain occurs frequently in both medical and surgical adult and pediatric patients (3). We found that our surgical patients were more likely than medical patients to have their pain assessed and more likely to receive analgesics. Johnston et al (6) reported that children who had undergone surgery were three to four times more likely to have received opioids than nonsurgical patients with similar pain intensity. It would seem from this and previous studies that when there is obvious justification for pain, such as surgery, more analgesia is used (4). Although not explicitly tested, another hypothesis for increased pain assessment and management on surgical units could be the increased presence of the APS on those units, allowing staff more opportunity for formal and informal consultation with expert pain nurses and physicians.

Despite having had pain assessed more frequently and having received more regular analgesia, patients followed by the APS were more likely to have had moderate or severe pain. Clearly, patients are referred to the APS because their pain is severe and/or difficult to manage. It is disappointing that at times their pain remained poorly controlled. In absolute numbers, four of the 26 patients who were being seen or had been seen by the APS indicated that they had 'a lot/severe pain' at the time of interview and 14 had 'a lot/severe pain' in the previous $24 \mathrm{~h}$. That four of these patients, three still actively under the APS, had severe pain at the time of interview suggests that some patients have pain that is not easily managed. It raises the possibility that for some subgroups of patients there is some pain that we are unable to relieve. Of the four patients with severe pain at the time of interview, three were currently under the APS. Three of the four had either chronic pain or acute chronic pain (Table 2).

To our knowledge, this is the only study that has evaluated the prevalence of chronic or persistent pain in hospitalized children. Twenty-seven per cent of our children or caregivers responded that the patient 'usually' had pain before admission to hospital. While time did not allow a full assessment or diagnosis, approximately $23 \%$ of children surveyed had persistent or recurrent pain (eg, recurrent abdominal pain, headache) that was likely chronic in nature. This requires further study. However, the high prevalence of pain 'usually present' before admission in our children is similar to that reported in several pediatric community studies (24-28). Furthermore, studies in adults have found that $20 \%$ to $27 \%$ of medical and surgical inpatients report a history of chronic pain $(2,4)$.

Results from studies evaluating sex differences in children's pain perception are equivocal; some studies demonstrate a higher likelihood of pain among females and others do not show such a difference (29). There were no sex differences in pain prevalence, pain intensity or likelihood of receiving analgesia in our inpatients.

There is evidence that both assessment and management of pain can be poorer for both non-English-speaking adults in the United States, and for those from visible minorities $(7,11,30$ 32). To our knowledge this has not been previously evaluated in children. For those who had this information recorded, 42.1\% either belonged to a minority or spoke English as a second language; it is possible that the majority of those for whom this information was not recorded were not from a minority and spoke English as a first language. If this assumption is made, then $36.5 \%$ of all interviewed patients belonged to a visible minority or spoke English as a second language. So, at least $36 \%$ of our patients belonged to either ethnic minority groups or spoke English as a second language, and their pain assessment documentation and pain management was not different from the larger group. We are encouraged that there does not seem to be cultural or language barriers leading to inferior assessment and management of pain in this population. This positive finding may reflect the multicultural mix of both staff and families at our hospital.

\section{Analgesia}

It was disappointing that analgesia was only received by $42 \%$ of those experiencing pain, and furthermore, that analgesia was only provided regularly for $30 \%$ of those in moderate or severe pain. While the PMI has not been validated for use in a pediatric setting, which we acknowledge as a limitation, other analyses of frequency and type of analgesia corroborate the results of our PMI analysis. The finding that $47 \%$ of the cohort who had pain during admission had a PMI less than zero, coupled with the finding that only one-quarter of patients with pain received regular analgesia, suggests inappropriate use of analgesics and undertreatment of pain. Despite the fact that in most cases the WHO standard of receiving regular balanced multimodal analgesia was not met, the majority of those children who received any analgesia found it helpful.

Obvious justification for pain, such as surgery or APS involvement, was associated with increased use of analgesics. There may be several explanations for this, including prescribing practices. We did not seek information on what was prescribed, we only have data on what was given; potentially more analgesia or more scheduled (as opposed to 'as needed' or 'on demand') analgesia was prescribed in surgical areas. It is certainly the practice of the APS to prescribe regular multimodal analgesia. When analgesics were used they were most likely to be intermittent, which likely represents prescribing practices. It has been suggested for decades that around-the-clock administration of analgesics is preferable to avoid the under medication that occurs with an 'as needed' or 'on demand' schedule $(3,33)$. 
While a full discussion of the reasons behind inadequate treatment of pain is beyond the scope of the present report, they are multifactorial, and for completeness are briefly mentioned. Knowledge barriers may exist among physicians and nurses regarding pain assessment, analgesic effectiveness and duration of action. Children receive substantially less analgesia than adults with similar conditions, suggesting that these barriers are even greater in children (34). The patients and families themselves may lack sufficient knowledge and understanding of what to expect and therefore put up with pain that could be relieved (3). Attitudes and beliefs concerning the use of opioids on the part of clinicians and families may also have impact on the treatment of children's pain. Brockopp et al (35) found $15 \%$ of their adult study population did not want additional pain medication for fear of either addiction or side effects. For some there may be cultural barriers or a cultural difference in pain behaviour and expectation between staff and patients, which can contribute to both difficulty in pain assessment and inadequate dispensing of pain medication (30). Furthermore, preconceived notions held by staff about pain in certain patient groups may also influence pain management (35).

\section{Pain assessment}

Despite standards mandating pain assessment, we found that documentation of pain assessment on the flowsheet was not done for the majority of patients. While the Hospital for Sick Children's Pain Assessment Policy was developed before the audit, the educational roll-out did not occur until later. Therefore, lack of knowledge regarding our policy likely contributed to our finding. It is possible that pain is being assessed ad hoc and either not being recorded or recorded somewhere other than the flow sheet. Regardless, pain assessment is the cornerstone of pain management and its documentation is important and will help make the pain problem more visible. It would seem logical that until pain assessment documentation is routine, the treatment of pain may remain suboptimal.

\section{Improvement initiatives}

The present study has been - and still is - a powerful motivator for change at the Hospital for Sick Children. The results have led to a number of strategies aimed at improving pain management. Audit and feedback can be an effective form of knowledge translation to improve professional practice (36); therefore, we have disseminated the results widely to all professional groups. Furthermore, unit specific analysis of results has been provided to the units to allow comparison with the total population and to instigate change from within each unit. Multiple educational initiatives are now in place, including orientation lectures for all nurses and pediatric residents. A link nurse system has been established so that there is a 'Pain Resource Nurse' evolving on each unit, who sits on the hospitalwide, interdisciplinary Pain and Sedation Committee, and cascades information back to the units. Furthermore, needs assessments are planned for all professional groups to identify both gaps in knowledge and how best to bridge them. Substantial funding has been obtained for research into effective methods of knowledge translation.

A new pain management clinical practice guideline is included in the Hospital Formulary, which contains links to the Pain Assessment Policy. Our hospital Quality and Risk Management colleagues have established pain assessment as a
'Unit Indicator'. Making pain part of a continuous quality assurance program offers the best hope to improving both its assessment and management. Bardiau et al (37) report positively on their experience of doing this with postoperative adult inpatients. McNeill et al (7) suggest that a systems approach is more likely to effect change. They counsel that three decades of traditional approaches involving education, policy development and regulatory mandates have failed to effect permanent change and effective pain management.

In addition to the strategies put in place for health care professionals, it is important to empower the patients and families with knowledge about pain and its management. To this end, together with the Aboutkidshealth team (the Hospital for Sick Children team of health professionals, medical writers, illustrators, animators and designers) we have developed a comprehensive Web site for and about pain in children and families that went online in 2005 (38). Additionally, plans are in place for a public relations campaign to raise the awareness of pain issues among children, families and staff.

\section{CONCLUSIONS}

We found that pain occurred commonly across all age groups and services. Pain was infrequently assessed. Analgesic therapy was largely single agent and intermittent, although very helpful when given. The Hospital for Sick Children in Toronto is a tertiary and quaternary pediatric centre that has an active APS and hospital wide policies for assessing pain and for the delivery of strong opioids, patient-controlled analgesia and epidurals. Nonetheless, we identified many areas that could be improved to optimize the assessment and treatment of pain. There has been a tremendous effort by many at the Hospital for Sick Children to make pain more visible and to improve its assessment and management. The present audit has been, and remains, a very useful tool to initiate change across our hospital. We have undertaken educational, research and policy initiatives and have put in place a system of key champions in each area. We have consolidated this by recognition of pain management as a key quality issue.

We aim to reaudit, using a similar prospective cross-sectional survey design, to document the effect of our interventions on the prevalence of pain, pain intensity, pain assessment documentation and management of pain. We hope that this report will act as a stimulus for other institutions to audit pain practice for children in their institutions.

ACKNOWLEDGEMENTS: Bruna Villella, Maureen Maloney and Judith McEwen helped with data acquisition. Lori Palozzi is tirelessly helping to disseminate the results. There were no competing interests and no sources of financial support.

\section{REFERENCES}

1. Taddio A, Katz J, Ilersich AL, Koren G. Effect of neonatal circumcision on pain response during subsequent routine vaccination. Lancet 1997;349:599-603.

2. Donovan M, Dillon P, McGuire L. Incidence and characteristics of pain in a sample of medical-surgical inpatients. Pain 1987;30:69-78.

3. Owen H, McMillan V, Rogowski D. Postoperative pain therapy: A survey of patients' expectations and their experiences. Pain 1990;41:303-7.

4. Abbott FV, Gray-Donald K, Sewitch MJ, Johnston CC, Edgar L, Jeans $\mathrm{ME}$. The prevalence of pain in hospitalized patients and resolution over six months. Pain 1992;50:15-28.

5. Mather L, Mackie J. The incidence of postoperative pain in children. Pain 1983;15:271-82. 
6. Johnston CC, Abbott FV, Gray-Donald K, Jeans ME. A survey of pain in hospitalized patients aged 4-14 years. Clin J Pain 1992;8:154-63.

7. McNeill JA, Sherwood GD, Starck PL. The hidden error of mismanaged pain: A systems approach. J Pain Symptom Manage 2004;28:47-58.

8. Phillips DM. JCAHO pain management standards are unveiled. Joint Commission on Accreditation of Healthcare Organizations. JAMA 2000;284:428-9.

9. Cummings EA, Reid GJ, Finley GA, McGrath PJ, Ritchie JA. Prevalence and source of pain in pediatric inpatients. Pain 1996;68:25-31.

10. WHO. WHO Pain Guidelines. Geneva: World Health Organization, 1986.

11. Green CR, Anderson KO, Baker TA, et al. The unequal burden of pain: confronting racial and ethnic disparities in pain. Pain Med 2003;4:277-94

12. McGrath PA, Koster AL. Headache measures for children: A practical approach. In: McGrath PA, Hillier LM, eds. The Child With Headache: Diagnosis and Treatment. Seattle: IASP Press, 2001:29-56.

13. Strohbuecker B, Mayer H, Evers GC, Sabatowski R. Pain prevalence in hospitalized patients in a German university teaching hospital. J Pain Symptom Manage 2005;29:498-506.

14. Cortínez LI, Brandes V, Muñoz HR, Guerrero ME, Mur M. No clinical evidence of acute opioid tolerance after remifentanil-based anaesthesia. Br J Anaesth 2001;87:866-9.

15. de Wit R, van Dam F, Loonstra S, et al. The Amsterdam Pain Management Index compared to eight frequently used outcome measures to evaluate the adequacy of pain treatment in cancer patients with chronic pain. Pain 2001;91:339-49.

16. Cohen MZ, Musgrave CF, McGuire DB, et al. The cancer pain experience of Israeli adults 65 years and older: The influence of pain interference, symptom severity, and knowledge and attitudes on pain and pain control. Support Care Cancer 2005;13:708-14.

17. Cohen MZ, Musgrave CF, Munsell MF, Mendoza TR, Gips M. The cancer pain experience of Israeli and American patients 65 years and older. J Pain Symptom Manage 2005;30:254-63.

18. Di Maio M, Gridelli C, Gallo C, et al. Prevalence and management of pain in Italian patients with advanced non-small-cell lung cancer. Br J Cancer 2004;90:2288-96.

19. Sherwood GD, McNeill JA, Starck PL, Disnard G. Changing acute pain management outcomes in surgical patients. AORN J 2003; 77:374,377-80,384-90.

20. McNeill J, Sherwood G, Starck P, Nieto B. Pain management outcomes for hospitalized Hispanic patients. Pain Manage Nurs 2001;2:25-36.

21. Ellis JA, O'Connor BV, Cappelli M, Goodman JT, Blouin R, Reid CW. Pain in hospitalized pediatric patients: How are we doing? Clin J Pain 2002;18:262-9.

22. Clancy CA, McGrath PJ, Oddson BE. Pain in children and adolescents with spina bifida. Dev Med Child Neurol 2005;47:27-34.
23. Chambers CT, Reid GJ, Craig KD, McGrath PJ, Finley GA. Agreement between child and parent reports of pain. Clin J Pain $1998 ; 14: 336-42$.

24. van Dijk A, McGrath PA, Pickett W, VanDenKerkhof EG. Pain prevalence in nine- to 13-year-old schoolchildren. Pain Res Manag 2006;11:230-40.

25. Taimela S, Kujala UM, Salminen JJ, Viljanen T. The prevalence of low back pain among children and adolescents. A nationwide, cohort-based questionnaire survey in Finland. Spine 1997;22:1132-6

26. Perquin CW, Hazebroek-Kampschreur AA, Hunfeld JA, et al. Pain in children and adolescents: A common experience. Pain 2000;87:51-8.

27. Roth-Isigkeit A, Raspe HH, Stöven H, Thyen U, Schmucker P. Pain in children and adolescents-results of an exploratory epidemiological study. Schmerz 2003;17:171-8.

28. Roth-Isigkeit A, Thyen U, Stöven H, Schwarzenberger J, Schmucker P. Pain among children and adolescents: Restrictions in daily living and triggering factors. Pediatrics 2005;115:e152-62.

29. McGrath PA, Holahan AL. Psychological interventions with children and adolescents: Evidence for their effectiveness in treating chronic pain. Seminars in Pain Medicine 2003;1:99-109.

30. Fenwick C, Stevens J. Post operative pain experiences of Central Australian Aboriginal women. What do we understand? Aust J Rural Health 2004;12:22-7.

31. Todd KH, Samaroo N, Hoffman JR. Ethnicity as a risk factor for inadequate emergency department analgesia. JAMA 1993;269:1537-9.

32. Todd KH, Deaton C, D'Adamo AP, Goe L. Ethnicity and analgesic practice. Ann Emerg Med 2000;35:11-6.

33. Hamers JP, Abu-Saad HH, van den Hout MA, Halfens RJ. Are children given insufficient pain-relieving medication postoperatively? J Adv Nurs 1998;27:37-44

34. Schechter NL, Allen DA, Hanson K. Status of pediatric pain control: A comparison of hospital analgesic usage in children and adults. Pediatrics 1986;77:11-5.

35. Brockopp D, Downey E, Powers P, et al. Nurses' clinical decisionmaking regarding the management of pain. Accid Emerg Nurs 2004;12:224-9.

36. Jamtvedt G, Young JM, Kristoffersen DT, Thomson O'Brien MA, Oxman AD. Audit and feedback: Effects on professional practice and health care outcomes (Cochrane Review). In: The Cochrane Library, Issue 3, 2003. Chichester, UK: John Wiley \& Sons, Ltd.

37. Bardiau FM, Taviaux NF, Albert A, Boogaerts JG, Stadler M. An intervention study to enhance postoperative pain management. Anesth Analg 2003;96:179-85.

38. About Kids Health Team. <www.aboutkidshealth.ca/Pain/PainHome.aspx?articleID $=6924 \&$ category ID $=\mathrm{PN}>($ Version current at January 23, 2008). 


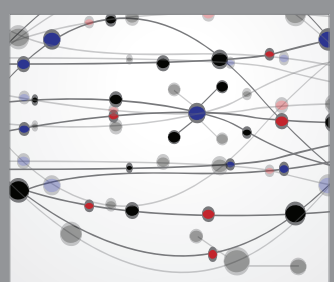

The Scientific World Journal
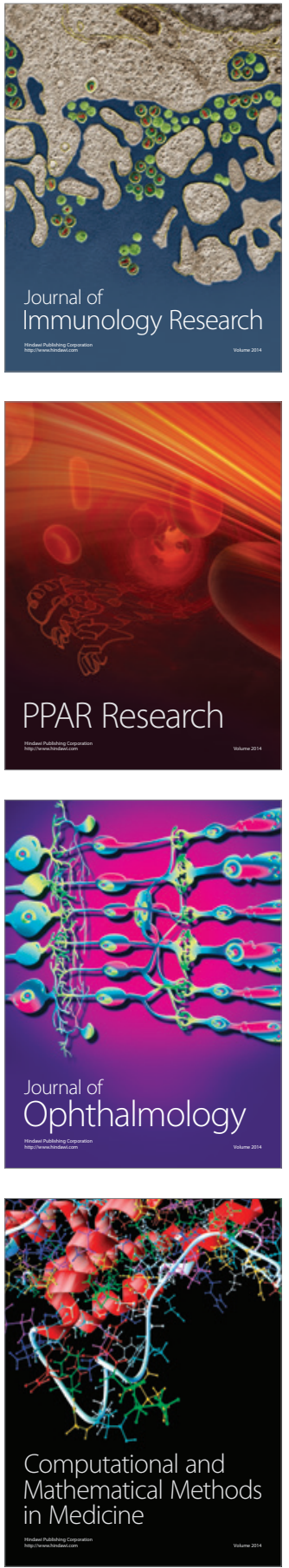

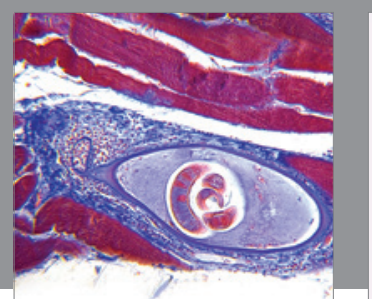

Gastroenterology Research and Practice

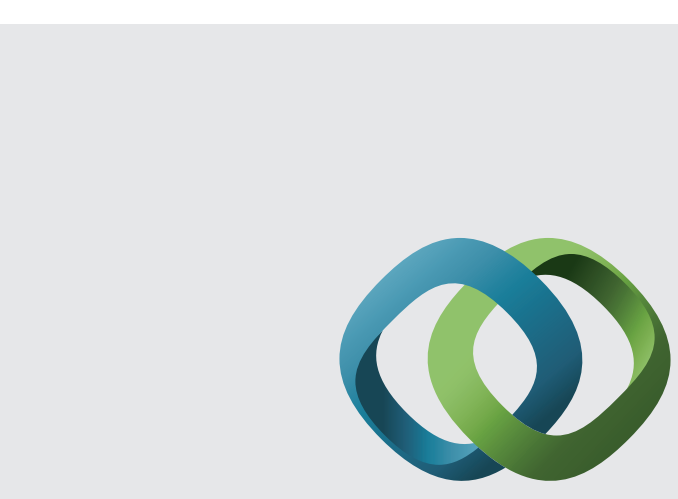

\section{Hindawi}

Submit your manuscripts at

http://www.hindawi.com
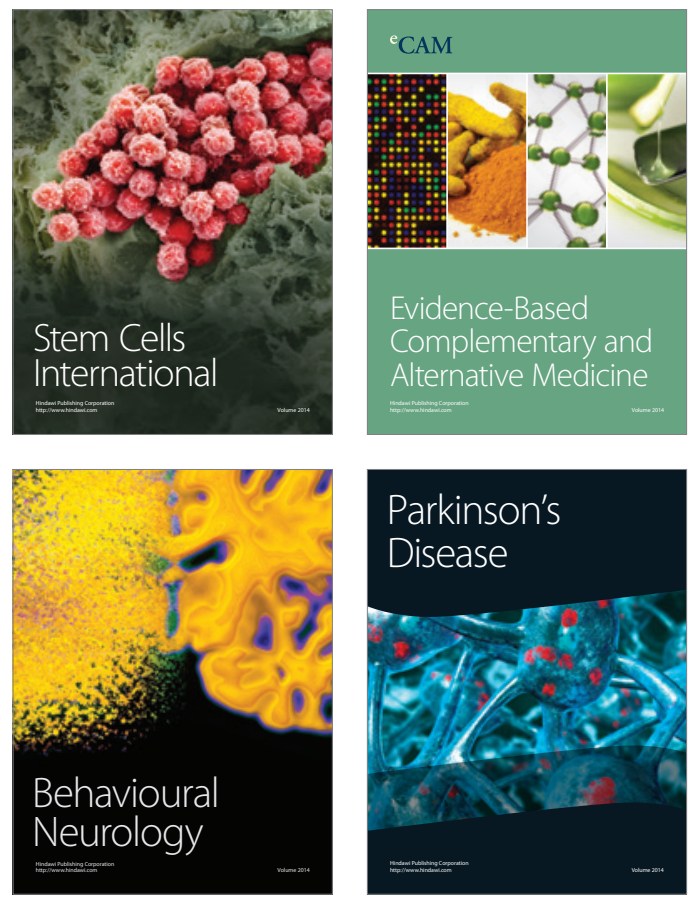
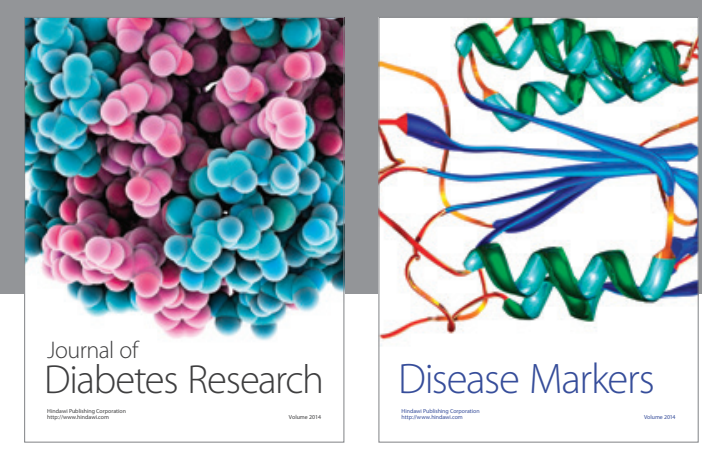

Disease Markers
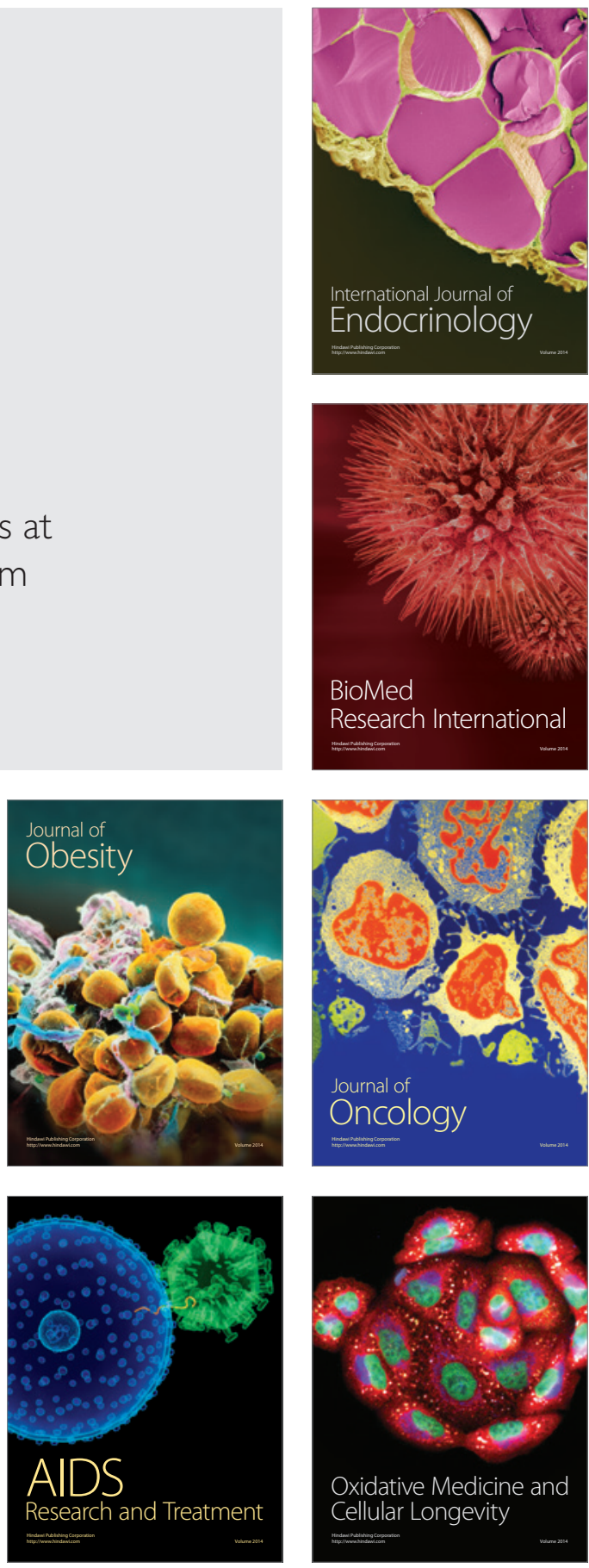